\title{
SOBRE LITERATURA, LEITORES E UTOPIAS
}

\author{
Georgina Martins ${ }^{1}$
}

\begin{abstract}
Resumo: Este artigo traz uma breve reflexão sobre o que vem a ser literatura e a sua importância na formação de crianças e jovens. Partimos da importância da formação crítica do leitor para entender os mais diversos assuntos, mesmo os mais espinhosos, como morte, sexualidade e violência. Nesse processo, cabe ao professor formar leitores competentes, críticos e atuantes. Para o sucesso dessa aprendizagem, é imprescindível que esse professor se aproprie com segurança e intimamente dos livros e da literatura para o exercício de prática de leitura do texto literário com prazer. Portanto, defendemos a utopia de o professor ser um ávido leitor capaz de contagiar todos seus alunos com a riqueza estética e cultural da literatura.
\end{abstract}

Palavras-chave: Ensino de literatura. Formação do leitor. Prazer da leitura.

\section{ABOUT LITERATURE, READERS AND UTOPIAS}

\begin{abstract}
This article presents a brief reflection about what is becoming literature and its importance in the formation of children and young people. We start from the importance of the critical formation of the reader to understand the most diverse subjects, even the thorniest ones, like death, sexuality and violence. In this process, it is up to the teacher to train competent, critical and active readers. For the success of this learning, this teacher needs to appropriate safely and intimately of books and literature for the practice of reading the literary text with pleasure. Therefore, we defend the utopia of the teacher being an avid reader capable of passing on to all his students the aesthetic and cultural wealth of literature.
\end{abstract}

Keywords: Literacy teaching. Reader training. Reading pleasure.

\section{Introdução}

Penso que a diferença mais importante entre literatura de gente grande e a que reconhecemos como sendo produzida para gente pequena seja o público alvo, o receptor, o leitor; neste caso, a criança. Dado que coloca o escritor diante de situações de escrita em que ele se vê obrigado a construir narrativas que sejam capazes de dialogar com as peculiaridades do que é ser

\footnotetext{
${ }_{1}^{1}$ Professora colaboradora de Literatura Brasileira do Departamento de Letras Libras da Faculdade de Letras da Universidade Federal do Rio de Janeiro; professora de Literatura do Programa de Mestrado Profissional/Profletras; escritora de livros para crianças e jovens.
} 
criança num mundo tradicionalmente dominado e construído por adultos. Esse escritor, antes de qualquer coisa, deve partir do princípio de que seu leitor é capaz de entender os mais diversos assuntos, mesmo os mais espinhosos, como morte, sexualidade e violência; dependendo, no entanto, de como esses temas são trabalhados na ficção que produz. Cuidados que incluem tanto a escolha do vocabulário, como a organização sintática do texto. Afora isso, penso também que o bom escritor, o que consegue se comunicar com seu leitor com profundidade e arte, sobretudo quando se trata de criança, é aquele que escreve, principalmente, sobre assuntos que gostaria de ler, sobre situações que desejaria desvendar, entender, ou mesmo sobre os desejos que gostaria de realizar.

$\mathrm{Na}$ outra ponta, igualmente implicado nesse processo, coloco o professor, por acreditar que, dada as configurações educacionais e sociais no mundo de hoje, caiba a ele a nobre tarefa de formar leitores competentes, críticos e atuantes, e para isso é imprescindível que esse professor possa se apropriar com segurança e intimidade do seu principal instrumento de trabalho - os livros, a literatura - para que desse modo ele possa ser de fato e de direito o Mestre/Maestro desse processo.

Daí a necessidade de propor nesse artigo uma breve reflexão sobre o que vem a ser literatura e a sua importância na formação de crianças e jovens.

\section{I}

No Livro Teoria da Literatura, Terry Eagleton destaca uma questão bastante complexa e de extrema importância para os profissionais cujo livro é o principal instrumento de trabalho. Para Eagleton, definir o que vem a ser Literatura não é tarefa fácil, pois essa definição deve levar em conta diversos aspectos, como, por exemplo, os diferentes tempos e contextos em que as narrativas são produzidas no mundo.

Dizer, por exemplo, que Literatura é a escrita imaginativa não resolve o problema, pois as diferenças entre fato e ficção, entre verdade histórica e verdade artística não são suficientes. As histórias em quadrinhos, por exemplo, não são verdadeiras, são narrativas fictícias; no entanto, não são consideradas Literatura por grande parte dos críticos que se dedicam ao tema. O mesmo podemos afirmar das narrativas religiosas: bíblicas, de matriz africana, orientais, etc, que tanto podem ser lidas como ficção ou como 
realidade histórica, a depender da crença ou descrença de cada leitor. Narrativas científicas, como a História, as Ciências Naturais e a Filosofia não são desprovidas de criatividade e imaginação, mas não podem ser chamadas de Literatura, no sentido literário do termo.

Já o escritor inglês, do século XIX, G. K. Chesterton, muito mais dedicado a escrever ensaios e análises críticas de obras do que a fazer ficção, defende que "a literatura é um luxo e a ficção uma necessidade" ${ }^{2}$. Isto porque ele partilha da crença de que todos temos necessidade de ficção, ou seja, de histórias, de fabulação. O homem cria e partilha histórias desde que está no mundo, como recurso para entender, para interpretar e construir esse mundo.

Um grupo de antílopes ${ }^{3}$ ou de qualquer outro animal sedento, ao se aproximar do leito de um rio e o encontrar seco, imediatamente sai em busca de outro rio, e se não o encontra acaba por morrer de sede. Os humanos, diante da mesma situação, depois de buscarem incessantemente outras fontes, antes de se entregarem à morte vão interpretar, rezar, dançar, buscar culpados e inventar milhares de rituais para convencer os espíritos a mandarem chuva. Isso é criar história, isso é ficção, e de acordo com Chesterton, é necessidade.

Para Nancy Husten, escritora canadense, a diferença entre nós e os animais é a mesma que existe entre a consciência e a inteligência, ou seja, o fato de existir e de se ter a consciência da existência. "A consciência é a inteligência mais o tempo, ou seja: a narratividade", a ficção, a fabulação, a criação, a mímeses (cópia interpretada e retrabalhada do objeto ou ação a ser imitada).

Em seu livro a Poética, Aristóteles se utiliza do conceito de mímeses (imitação) para explicar o que ele pensava sobre Arte Poética. Para ele o ser humano é o animal mais mimético de todos, desde a infância ele realiza a mímeses, pois é desse jeito que apreende o mundo a sua volta, que o entende e o interpreta. É também o único que realiza a mímeses com consciência, além de encarar esse processo como uma ação prazerosa. ${ }^{4}$

Então isso quer dizer que todo ser humano é poeta? Não, mas quer dizer que todo ser humano, se quiser, pode ser, mas para sê-lo precisa

\footnotetext{
${ }^{2}$ CHESTERTON, 2015.

${ }^{3}$ HUSTON, 2010.

${ }^{4}$ ARISTÓTELES, 2015.
} 
reconhecer o que decide imitar (gente, objeto, animal, ação), para depois, manipular e elaborar esse material, dando-lhe forma de poesia, canto, drama, tragédia, etc. Segundo Aristóteles, isso pode ser feito de três formas: como as coisas eram ou são; como são ditas ou se considera que sejam; ou como deveriam ser (ideal, evasão), e além disso o resultado desse processo deve suscitar sentimentos de todo tipo: compaixão, pavor, ira, amor, alegria, tristeza, etc. A diferença entre o poeta e o historiador, para o filósofo, consiste no fato de que o historiador narra os fatos que aconteceram e o poeta o que poderia acontecer ou o que ele deseja que aconteça. Séculos depois, o escritor russo, Vladimir Nabokov, em consonância com Aristóteles, nos dá a sua definição sobre o que é literatura:

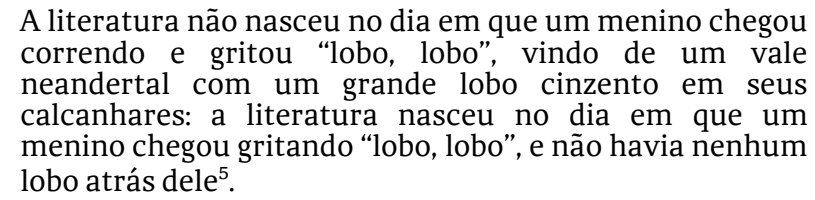

No livro A Personagem de Ficção, Anatol Rosenfeld - escritor de origem alemã - afirma que tudo aquilo que aparece fixado por letras é literatura: obras científicas, avisos, bilhetes, manuais e etc.; no entanto, existe a definição do que vem a ser "As belas letras", mas isso também não dá conta da nossa pergunta, porque o que pode ser belo para um povo, para uma época, pode não ser belo para outro. Nesse sentido, o que talvez possa nos ajudar é pensar como Roman Jakobson (crítico russo), que define a Literatura como sendo uma "violência" organizada contra a fala comum. Para ele, a Literatura transforma e valoriza a linguagem comum, afastando-a da fala cotidiana. A Literatura emprega a linguagem de uma forma peculiar, ou seja, especial, poética. Podemos dizer, ainda, que a Literatura é um discurso não pragmático, ou seja, ao contrário dos manuais e dos bilhetes que deixamos para alguém, ela não tem nenhuma finalidade prática imediata.

Então para começarmos a pensar mais profundamente no assunto, sabendo que não vamos conseguir respostas esclarecedoras, citamos Ernest Cassirer - “afastando-se da realidade e elevando-se a um mundo simbólico, o homem, ao voltar à realidade, lhe apreende melhor a riqueza e profundidade"- e Goethe: "através da arte distanciamo-nos ao mesmo tempo em que nos aproximamos da realidade".

${ }^{5}$ NABOKOV, 2015. 
Jochen Gerz, fotógrafo alemão que, ao invés de fotografar as pesadas portas de ferro e os fornos de um campo de concentração na Alemanha, transformado em museu, optou por representar todo aquele horror e violência fotografando o que havia de mais banal naquele lugar: as placas de sinalização, como "Toaletes", "Saída", "Chame o padre" e "Administração". ${ }^{6}$

Ao expor essas fotos, o artista, não só elevou a realidade a um nível simbólico, como ainda promoveu a "violência organizada contra a fala comum". Palavras inocentes e vulgares, que na sua origem não queriam dizer nada além de fornecer informações objetivas, foram, pelas mãos (olhar) do artista, transformadas em objeto de arte, e desse modo puderam expressar e representar a crueldade daquela situação, uma vez que as mesmas, em seus significados originais, em estado de dicionário, não tinham nenhuma função para os prisioneiros desses campos de crueldades. Desse modo, a obra desse artista deixou de ser uma mera fotografia do real e foi elevada ao status de arte.

\section{II}

Depois dessa breve tentativa (inglória) de definir o que é literatura, precisamos ir um pouco mais além para, pelo menos, tocarmos, de leve que seja, o Santo Graal do nosso ofício com os livros, que pode ser representado pela pergunta: mas, a literatura serve pra quê mesmo, heim?

A resposta dada por alguns pensadores da área sempre me incomodou muito: "a literatura não serve pra nada, ela é arte porque não tem utilidade prática”. Sim, é claro que não pagamos nossas contas lendo poesia ou prosa para os gerentes dos bancos, tampouco teremos nossa vida prática organizada se passarmos todo nosso tempo deitados em berço esplêndido lendo literatura, mas até aí dizer que ela "não serve pra nada" é um pouco demais. Seriam a literatura e as outras artes inúteis? O livro/manifesto do italiano Nuccio Ordine, professor de literatura na Universidade da Calábria, advoga em prol dos "saberes cujo valor essencial está totalmente desvinculado dos fins utilitaristas”, e nesse rol, ele inclui, é claro, a literatura.

\footnotetext{
${ }^{6}$ LEENHARDT, 1990.
} 
Saberes que estão a serviço do crescimento espiritual e cultural da humanidade, e que por isso contribui para nos tornarmos melhores. ${ }^{7}$

É partindo dessa premissa que, na qualidade de professora, penso em como poderia convencer meu aluno a estudar uma coisa que eu mesma achasse que não teria nenhuma utilidade? Como esperar que os livros que recomendo a leitura possam competir com os jogos cada vez mais sofisticados, que qualquer guri pode encontrar na internet e com eles satisfazer sua necessidade de ficção, se eu já apresento esses livros como algo que não tem nenhuma utilidade para a vida deles? Por que não apresentar, então, a literatura com a mesma paixão do dramaturgo Romeno Eugène Ionesco? "A poesia, a necessidade de imaginar e de criar é tão fundamental quanto respirar. Respirar é viver e não fugir da vida"8. Por que não desejarmos literatura como desejava o escritor francês Victor Hugo:

Mas se quero ardentemente, apaixonadamente, o pão para o operário, o pão para o trabalhador, que é meu irmão, juntamente com o pão para a vida, quero o pão para o pensamento, que também é o pão da vida. Quero multiplicar o pão do espírito como o pão do corpo ${ }^{9}$

Mas para que possamos alimentar essa utopia é fundamental e imprescindível tornar-se um professor leitor, mas não um leitor qualquer, mas um ávido leitor, pois somente um leitor apaixonado é capaz de contagiar aquele que não vivencia experiência da leitura. Um aluno que nunca vê o seu professor lendo ou portando livros de literatura, dificilmente será convencido por esse profissional que ler é bom e necessário; mas necessário para quê? Já vimos que com literatura não pagamos contas, não organizamos nossa casa e não colocamos comida na mesa, a menos que sejamos um escritor best seller, o que é muito difícil de acontecer no Brasil. No entanto, se já vimos também que todo mundo gosta e precisa de ficção - haja visto a audiência das novelas, as filas dos cinemas ou os filmes baixados em casa, os jogos de computadores, o interesse pela vida dos outros e etc -, podemos ter a certeza de que há chance para a literatura, sobretudo se nós, professores, formos capazes de convencer nossos alunos do poder de sedução que pode ter um romance, um conto, uma poesia.

\footnotetext{
7 ORDINE, 2016.

8 IONESCO, 2016.

${ }^{9}$ VICTOR, 2016 p. 112.
} 
Nas séries iniciais isso é muito mais fácil de acontecer, pois nessa fase são os contos de fadas, as histórias de animais que falam e de objetos que ganham vida, que partilhamos com nossas turmas. Narrativas que já nasceram seduzindo, encantando, como afirma o historiador francês Jules Michelet: "Esses contos têm uma parte histórica, evocam as grandes fomes. Em geral, porém, pairam bem acima de toda a história: nas asas do pássaro azul, numa eterna poesia, expressam nossos desejos, sempre os mesmos, a imutável história do coração". ${ }^{10}$

Isto posto, o que fazer depois das séries iniciais para que nossos alunos se interessem pela literatura? Em primeiro lugar, é preciso conhecer as diferentes realidades que temos em uma sala de aula, sobretudo quando atuamos no âmbito da educação pública, espaço que muitas vezes testemunha a convocação precoce de parte dos nossos alunos para contribuir com o sustento da família, situação que nos coloca diante de uma complexidade muito maior para alcançarmos nosso desejo de formar leitores. Nesse sentido, é crucial que a literatura, parafraseando Roland Barthes ${ }^{11}$, dê provas de que deseja esses alunos. Que os textos os chamem, os convoquem, os atraiam, despertando sonhos e desejos. Mas, como fazer isso?

\section{III}

Para ilustrar essa reflexão, partilho aqui um trecho das minhas memórias de leitura no Colégio Municipal Roberto Silveira, em Mesquita, uma cidade pobre do Rio de Janeiro.

\section{Helena e Os Meninos}

Estava com treze anos quando conheci Helena. Foi seu Gentil quem nos apresentou a ela. Não sei se todos os alunos da turma gostaram dela como eu, que até hoje lembro das tranças grossas, "da face de um moreno pêssego e dos olhos suspeitosos". Descrição um tanto sofisticada para nossa idade, mas que, mesmo sem entender direito, achei tão bonita que desejei ser Helena; meus cabelos eram ralos e as tranças que minha mãe fazia nunca ficavam grossas. Além do que, eu imaginava o quanto deveria ser belo um rosto da cor

${ }^{10}$ MICHELET, 1992.

${ }^{11}$ BARTHES, 1996. 
de pêssego. Quanto a olhos suspeitosos, embora não fizesse a menor ideia do que queria dizer, achei lindo.

Helena tinha uns dezesseis ou dezessete anos quando foi morar na casa do conselheiro Vale. Ele acabara de falecer e deixara em testamento a confissão de que a moça era sua filha, revelação que mudou a vida na chácara onde residiam Estácio e D. Úrsula, filho e irmã do conselheiro. Estácio até então julgava ser filho único.

Foram mais ou menos essas informações que seu Gentil nos deu quando mandou que lêssemos Helena. Era o ano de 1972 e eu estudava no Colégio Municipal Roberto Silveira, um colégio novinho, recém-inaugurado, onde todos os professores gostavam de ler; até a equipe de orientação educacional orientava nossas leituras. Lembro que o psicólogo da escola, que também era médico, receitava livros aos alunos que iam procurar sua ajuda. A mim, ele chegou a receitar dois: uma publicação da Ediouro sobre Freud e o inconsciente, e Yoga para nervosos do profo Hermógenes. Remédios que julgava pudesse contribuir para apaziguar meu coração adolescente, o que certamente não se deu, posto que até hoje não há cura para esse tipo de moléstia. Em contrapartida, o prazer que aquelas leituras me proporcionaram justificou o tratamento.

Seu Gentil foi nosso professor de Português durante todo o Ginásio e nos apresentou a muitos personagens. No primeiro ano, assim que começaram as aulas, ele mandou que lêssemos Os Meninos da rua Paulo, o que fiz com muito gosto. Lembro que deixei de lado as brincadeiras na rua onde eu morava para participar das aventuras daquele terreno baldio de Budapeste, comandada por meninos cujos nomes - Nemecsek, Boka, Géreb, Csónakos sequer conseguia pronunciar, mas que se tornaram tão próximos de mim que até hoje não consigo me conformar que o pequeno Nemecsek tenha sacrificado a própria vida para proteger do ataque do grupo inimigo, o terreno onde brincavam.

Tenho uma vaga lembrança de que alguma aluna reclamou do livro, alegando que o tema não era feminino. Ainda bem que seu Gentil ignorou a reclamação e manteve a escolha da leitura, pois logo nas primeiras páginas pudemos perceber que tínhamos em mãos uma deliciosa e pungente aventura de meninos que, como nós, também estavam vivos, e por isso acreditavam no sonho. 
Outros autores vieram e sob protestos de vários alunos, seu Gentil nos disse que teríamos um mês para concluir a leitura de mais um livro e nos prepararmos para fazer a prova, já que o final do ano se aproximava. Tratavase de Éramos Seis, novela narrada a partir das memórias de dona Lola, personagem que fez das tripas coração para criar seus quatro filhos na cidade de São Paulo, no ano de 1943, em plena 2 a guerra mundial.

Em menos de uma semana eu não só conhecia o drama de dona Lola, como ainda torcia para que Alfredo voltasse pra casa, e Carlos não morresse no campo de batalha. Por tratar-se de uma narrativa sobre um cotidiano que eu desejava, minha identificação com a trama foi imediata. Queria ser Isabel, a filha de dona Lola, sobretudo porque achava muito bonito pertencer a uma família grande que se reunia em volta de uma mesa para fazer as refeições; coisa impossível em uma meia-água de três cômodos que meu pai nunca conseguiu acabar de construir, e que sequer tinha mesa. Lá éramos apenas três: eu, meu pai e minha mãe.

Por isso as reclamações de dona Lola a respeito da vida que levava me pareciam descabidas e exageradas. Como eu poderia compreender que em uma casa com jardim, "com portãozinho de ferro e duas janelas de frente", onde a família se reunia para fazer as refeições, pudesse caber tanta reclamação? Minha confusão aumentava na medida em que dona Lola se punha, de memória, a descrever os ambientes daquela casa onde ela havia morado com sua família:

“As duas janelas da frente eram do escritório e vi dentro dele a escrivaninha grande onde eles estudavam. Ao lado, numa parede, havia uma estante com livros; havia também duas cadeiras, e um tapetinho feito de meias velhas por minha irmã Clotilde. Passei pelo pequeno vestíbulo, onde havia um chapeleiro e entrei na sala de jantar. Era uma sala grande e de um lado havia um recanto com um sofá, duas poltronas e uma cadeira de balanço, tudo coberto com brim pardo, por causa das crianças; nesse lugar eu passava o dia, recebia minhas visitas e fazia tricô para ganhar algum dinheiro."

Tropecei no vestíbulo da casa de Dona Lola e fiquei dias tentando saber do que se tratava. Na minha casa não havia um dicionário onde eu pudesse consultar o significado de vestíbulo, palavra que ninguém da minha linhagem, incluindo tias e primos, era capaz de decifrar, pois não fazia parte da herança cultural que as famílias de meu pai e de minha mãe haviam transmitido aos filhos. Desse legado, minha mãe trouxera casa de sapê, saibro

Pontos de Interrogaçầo, v. 7, n. 2, jul.-dez., p. 121-131, 2017. 
e cacimba; meu pai, por sua vez, sabia de telhados de zinco, laje de concreto, meia-água e parede emboçada. No entanto, mesmo sem saber o significado eu percebia que se tratava de um espaço nobre, daqueles que só as casas dos ricos possuem. Por isso a pobreza que dona Lola ostentava nunca me convenceu, mas isso não me impediu de na época achar que Éramos seis fosse o livro da minha vida, na verdade da vida que eu gostaria de ter. Eu lia na varanda da nossa meia-água, imaginando que as latas de leite Glória onde minha mãe plantava suas flores fossem o jardim de Dona Lola.

\section{Considerações finais}

É claro que essas memórias se referem a um tempo em que os livros, eram praticamente, o único lugar em que crianças e adolescentes podiam conhecer os segredos do mundo adulto, daí a facilidade maior em seduzir para a literatura. Eram nos livros e em algumas revistas que podíamos ter contato com os detalhes "picantes" da nossa existência, via histórias sobre paixões, morte, namoro, casamento, sexo. Diferente do que temos hoje, tempo em que desde muito cedo o cotidiano da criança é atropelado por toda sorte de informações sem que ela precise abrir um livro. Constatação que nos obriga a pensar em uma infinidade de estratégias se quisermos de verdade formar leitores.

\section{Referências}

ARISTÓTELES. Poética. São Paulo: Editora 34, 2015.

BARTHES, Roland. O prazer do texto. São Paulo: Perspectiva, 1996.

CHESTERTON, G.K. O Defensor. Campinas: CEDET, 2015.

EAGLETON, Terry. Teoria da Literatura. São Paulo: Martins Fontes, 1983.

HUSTON, Nancy. A Espécie fabuladora. Porto Alegre: LPM, 2010

IONESCO, Eugène, in ORDINE, Nuccio. A inutilidade do inútil. Rio de Janeiro: Zahar, 2016. 
LEENHARDT, Jacques. O que se pode dizer da violência? In LINS, Ronaldo L. Violência e Literatura. Rio de Janeiro: Tempo Brasileiro, 1990.

MICHELET, Jules. A feiticeira. Rio de Janeiro: Nova Fronteira, 1992.

NABOKOV, Vladimir. Lições de literatura. São Paulo: Três estrelas, 2015.

ORDINE, Nuccio. A inutilidade do inútil. Rio de Janeiro: Zahar, 2016

POSTMAN, Neil. O desaparecimento da infância. São Paulo: Graphia, 1999.

ROSENFELD, Anatol; PRADO, Décio de Almeida; GOMES, Paulo Emílio Sales. $A$ personagem de ficção. São Paulo: Perspectiva, 1992.

HUGO, Victor, in ORDINE Nuccio. A inutilidade do inútil. Rio de Janeiro: Zahar, 2016.

Recebido em: 17/11/2017

Aprovado em: 16/12/2017 